\title{
A study of the most important image quality measures
}

\author{
Rogério M. Kinape ${ }^{1}$, Mardson F. Amorim² \\ ${ }^{1}$ College Cenecista Presidente Kennedy, Street Rui Barbosa, 541 - Campo Largo Paraná, 83601-380 \\ ${ }^{1,2}$ Programa de Pós-Graduação em Informática Aplicada (PPGIA), \\ Pontifical University Catolic of Paraná (PUC/PR), Street Imaculada Conceição, 1155 - Prado Velho - Paraná \\ Brasil, 80.215-901. \\ Fone: +55 41330 1670, Fax: +55 413301669 .
}

\begin{abstract}
At the present time there are several statistical computer measures in existence that can be used to quantify the gain or loss of image quality. The challenge consists in guaranteeing that these measures may be reliable for a given goal. This paper presents a study and comparison between several commonly used quality measures (signal/noise relation, average quadratic error, histogram cross-correlation, and pixel correlation) applied to digital images that underwent computer processing to affect their quality.
\end{abstract}

Keywords: Image quality measures, multimedia streaming, quality loss.

\section{Introduction}

Any processing applied to an image may cause in it an important loss of information or quality. In medicine, this kind of loss can cause an incorrect interpretation that may lead to uncountable damage for the lives involved in the image diagnosis [9]. On the other hand, in order to be able to transmit images through a communication network, whether it is a Local Area Network (LAN), the Internet or a wireless network, we have to take into consideration several obstacles, such as possible low transmission rates [9] and the cover area of wireless networks [9]. Therefore, we have to think carefully on the desired Quality of Service (QoS) and take into consideration the limitations of the transmission means as well as the desired image quality. In this context, this paper studies the sensibility and precession of the techniques used to measure the loss of quality in images that have suffered a certain degradation.
The software used to implement the measures of quality was Matlab ${ }^{\circledR}$. The videos were produced with a Creative Go Plus ${ }^{\circledR}$ webcam, and then converted to the streaming format by means of the Microsoft Windows Media ${ }^{\circledR}$ encoder. The reception was achieved with Windows Media Player ${ }^{\circledR}$.

Fifteen films captured by the webcam were used, having each of them a duration of two minutes. Transmissions were configured for the usual rates: 9,6kbps (approximately 10kbps), $14.4 \mathrm{kbps}, 19.2 \mathrm{kbps}, 28.8 \mathrm{kbps}, 33.6 \mathrm{kbps}, 56 \mathrm{kbps}$, $64 \mathrm{kbps}, 128 \mathrm{kbps}, 256 \mathrm{kbps}, 384 \mathrm{kbps}$ and $512 \mathrm{kbps}$. Two frames were captured at each speed: one from the original film and another from the film that was received by the streaming player. To be sure that the captured frames corresponded to the same moment in time, a little blue mark was inserted in frame number 60 of the original video. This procedure made it easy to identify that frame within the video that was received by the Windows Media Player. The image samples were captured twice from the films in order to better guarantee the results. The compared measures were: signal/noise relation [1][2][4][5][6], average quadratic error [1][2][4][5], cross-correlation between histograms [1][2][4], and correlation between image coefficients [1][2][4]. We shall now illustrate the equations of each quality measure.

The signal-noise relation was calculated with expression:

$$
S N R=-20 \cdot \log \left[\frac{1}{I . J} \cdot \sum \sum \frac{f(i, j)-f^{\prime}(i, j)}{255^{2}}\right]
$$

$$
\text { Equation } 1 \text { - Signal/Noise relation }
$$

The average quadratic error measure was obtained from expression:

\section{Methodology}




$$
E E=\sqrt{\frac{1}{I . J} \cdot\left[f(i, j)-f^{\prime}(i, j)\right]^{2}}
$$

Equation 2 - Average quadratic error

The cross-correlation was calculated using expression:

$$
x \text { corr }=\frac{\sum\left[f(i, j) \cdot f^{\prime}(i, j)\right]}{\sqrt{\sum f(i, j)^{2} \cdot \sum f^{\prime}(i, j)^{2}}}
$$

\section{Equation 3 - Standard Cross-Correlation}

Where:

SNR = signal/noise relation given in decibels $(\mathrm{dB})$;

$\mathrm{EE}=$ average quadratic error given in RMS;

Xcorr = standard cross-correlation;

$\mathrm{I}=$ height of the image;

$\mathrm{J}=$ width of the image;

$f(i, j)=$ image without quality loss;

$f^{\prime}(i, j)=$ image with quality loss

The set of images that were used in the experiment contained a total of 660 images.

For calculation purposes, the images were broken into its respective colour components [3][7][8][10].

The equations were implemented in Matlab. The calculation results were tabulated in function of the transmission rates.

\section{Results}

The values of the results that we obtained are shown in graphs 1, 2, 3 and 4 . Since it is not possible to show all the test images that were used to obtain them, we shall only include a selection of images with their corresponding results.

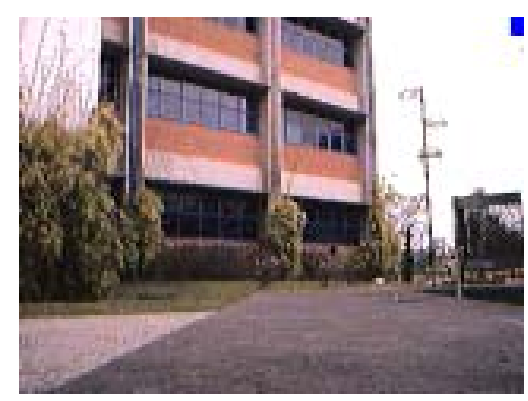

Figure 1 - Image000 without quality loss

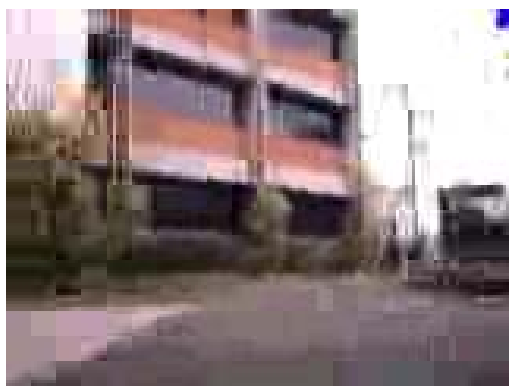

Figure 2 - Image000 with quality loss, $10 \mathrm{kbps}$ rate

Figure 1 is a video captured frame without loss of quality denoted as Image 000 in tables 1, 2, 3 and 4 . Figure 2 is the same frame having suffered a conversion to the streaming format and transmitted at a $10 \mathrm{kbps}$ rate. The signal/noise relation was $17.3191 \mathrm{~dB}$, the average quadratic error was 34.7279 , the cross-correlation was 0.4223 , and the pixel correlation 0.8967 .

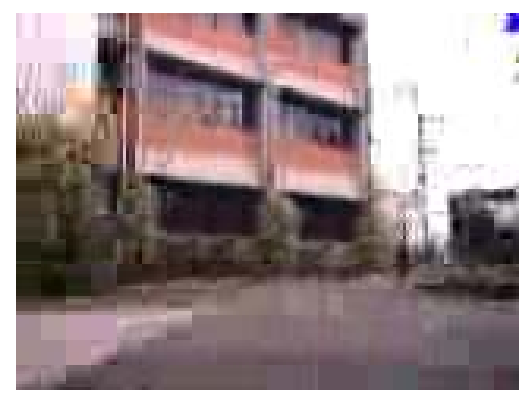

Figure 3 - Image000 with quality loss, $14,4 \mathrm{kbps}$ rate

Figure 3 was captured from the same video that generated figures 1and 2 . The transmission rate for figure 3 was $14.4 \mathrm{kbps}$. Since the transmission rate was higher, the compression was rate lower and the amount of quality loss was also lower. Since the amount of loss was lower, the signal/noise relation value is higher than the one obtained for figures 1 and 2 . The quadratic error is smaller while the values of the correlations are higher. The values that were measured using the techniques of figures 1 and 3 are: signal/noise relation $23.2767 \mathrm{~dB}$, average quadratic error 17.4985, cross-correlation between histograms 0.4314 , correlation between pixels 0.9836 . 


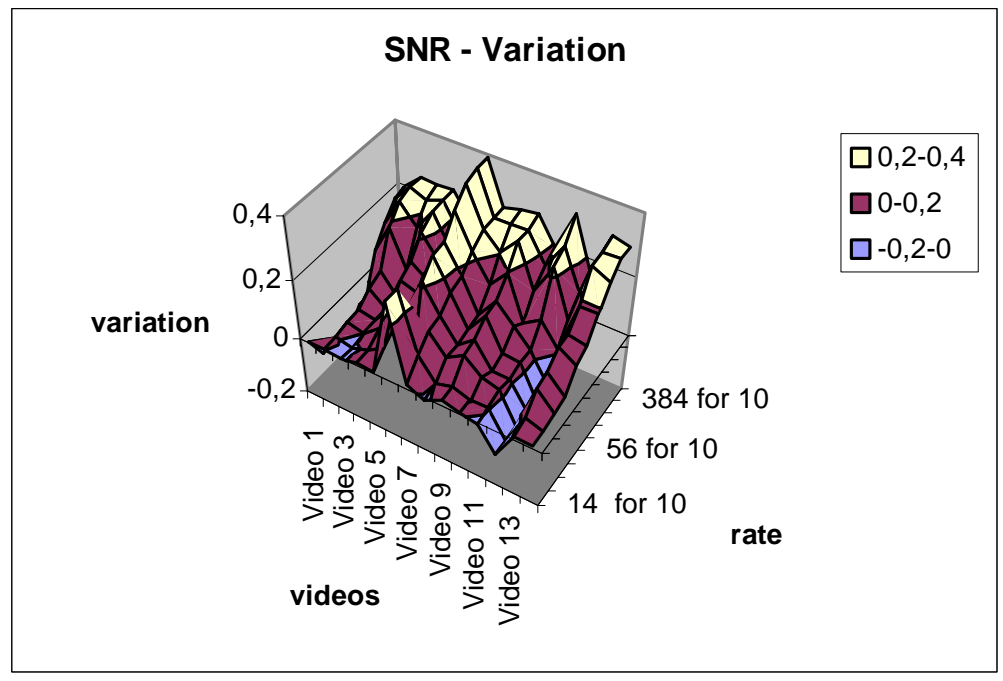

Graph 1

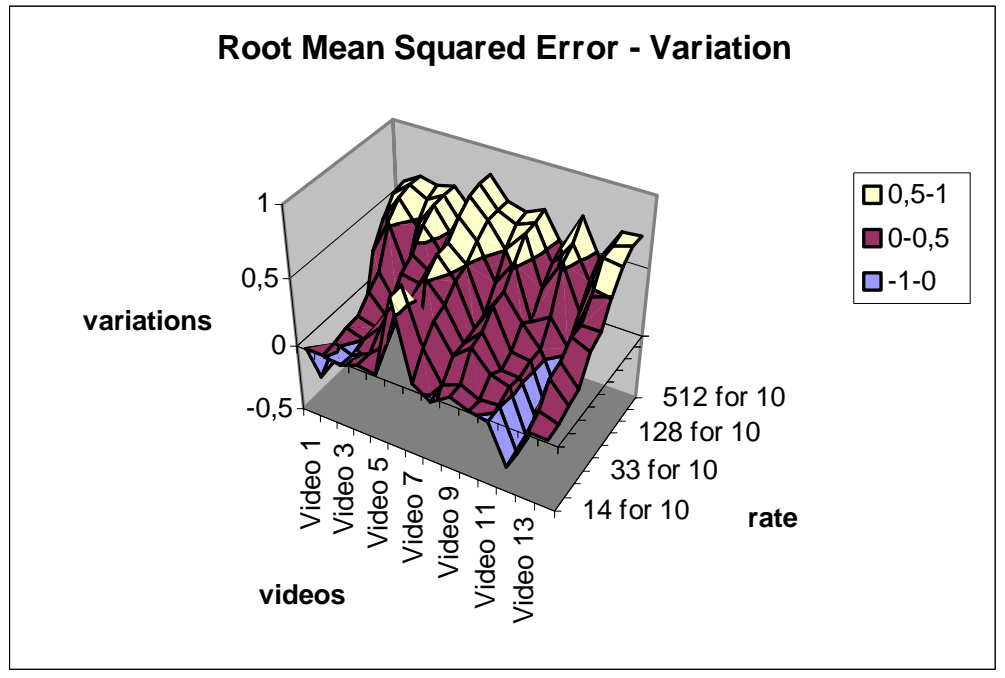

Gráfico 2

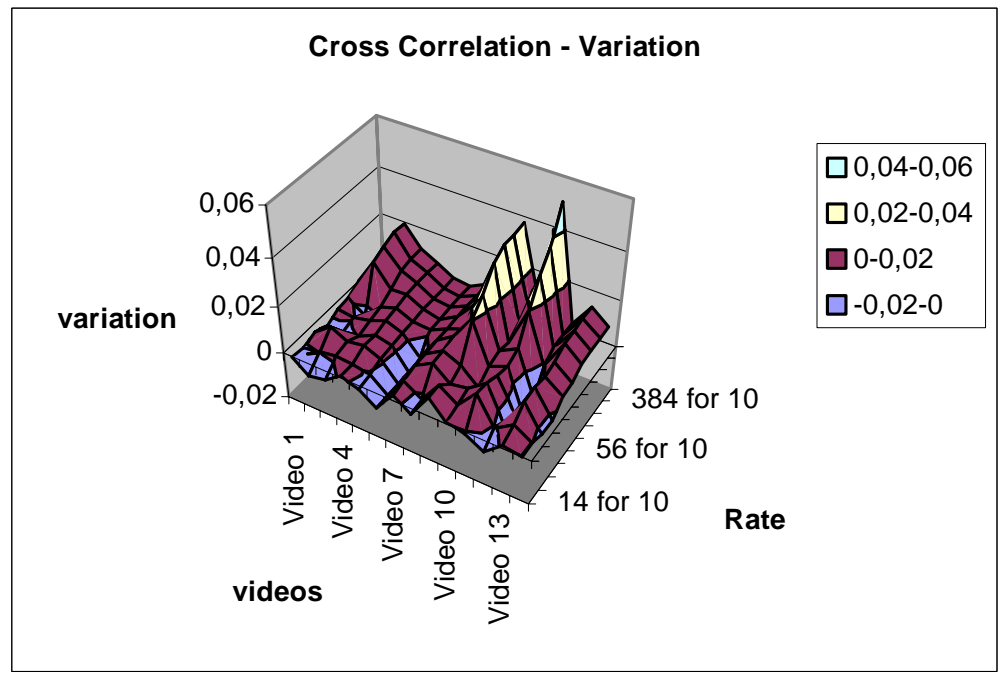

Graph 3 


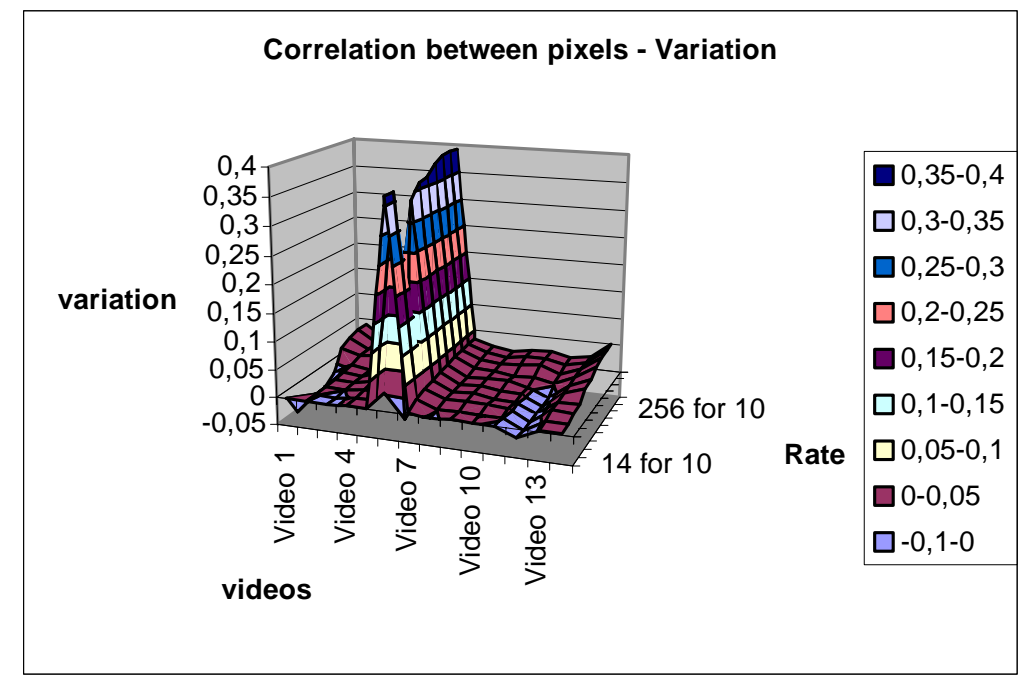

Graph 4

\section{Conclusions}

When analysing graphs $1,2,3$ and 4, one can conclude that the measures of quality that were most sensitive to changes in the quality of the images were the signal/noise relation and the average quadratic error, being the signal/noise relation the one with which the best results were obtained since the measured variations were higher (the curves in the graph were more pronounced). The cross-correlation between histograms and the correlation between pixels did not show good sensibility to changes in image quality (the graphs suffered practically no alteration while changing the transmission rates), therefore not showing themselves adequate for quantitative analyses of image quality loss.

\section{Acknowledgements}

We would like to thank Motorola do Brasil for the encouragement and financing of this scientific research.

\section{References}

[1] Ahumada, A. Jr., "Putting the noise of visual system back in the picture". Josa A, 4, 2372-2378, 1987.

[2] Ahumada, A. Jr., "Luminance-model-Based DCT quantization for color image compression". SPIE Proc, 1666, 365-374, 1992.

[3] Barrett, H.H., "Evaluation of imagem quality through linear discriminant models". SID Digest, 23, 871-873, 1992.
[4] Barten, P., "Evaluation of subjective image quality with the square foot integral method". Josa A, 7,, 2024-2031, 1990.

[5] Barten, P., " The SQRI as a measure for VDU image quality". SID Digest, 23, 867-870, 1992.

[6] Budrikis, Z., "Visual fidelity criterion an modeling". Proc. IEEE, 60, 771-779, 1972.

[7] Burt, P., Adelson, E., "The laplacian pyramid as a compact image code". IEEE Trans., COM-31, 532-540, 1983.

[8] Lenzi, K. G., Gaspar, O. Jr., "Matching eficiente de cantos", PUCPR, 2001.

[9] Shimizu, K. "Telemedicine by mobile communication". IEEE, 18, 32-44, 1999.

[10] Watson, A.B.,"Detection and recognition of simple spatial forms", O.J. Braddick e A.C. Sleigh, eds., Physical and biological processing os images, Springer-Verlang, Berlin.

\section{Bibliography}

Dougherty, Edward R., Introdution real-time imaing, Washington: IEEE Press

Jain, Anil K., Fundamentals of Digital Image Processing, New Jersey: Prentice-Hall International, 1989.

Russ, John C., The Image Processing Handbook, North Carolina: CRC Press, 1992.

Spiegel, Murray R., Estatística, $3^{\mathrm{a}} \mathrm{ed}-\mathrm{São}$ Paulo: Makron Books, 1993. - (Coleção Shaum) 